\title{
Comparing Google Groups Use by Evaluating Flow Experience and Generated Messages in Laptop and Desktop Higher Education Students
}

\author{
Steven Lopes Abrantes \\ Polytechnic Institute of \\ Viseu, Viseu, \\ Portugal
}

steven@di.estv.ipv.pt

\author{
Luis Borges Gouveia \\ Faculty of Science and Technology, \\ University Fernando Pessoa, Porto, \\ Portugal
}

Imbg@ufp.edu.pt

\begin{abstract}
The main purpose of this study is to establish whether the user is feeling the flow experience and what type of messages are sent by the participants when using Google Groups through users that have laptops or desktops. In the context of this study, information has been gathered through a survey, applying the five dimensions of the flow state. At the end of the study, after analyzing the gathered information, it was possible to conclude that students have experimented with the flow experience and that it had a positive effect on their learning experiences, but the students that used the laptops were more engaged in the flow experience than the students that used desktops. For messages, the data was retrieved from Google Groups. Relatively, from the type of messages of users with laptop, we can conclude that these users sent more messages classified as Very Good, Good, Positive and also messages classified as not significant, than the users with desktop.
\end{abstract}

Keywords: Google Groups; Messages Types; Flow Experience; Mobile Devices; Desktop Computing; Collaborative Environments; Higher Education.

\section{Introduction}

The use of information and communication technologies (ICT) in learning can be considered as an evolution in distance education. This type of learning, called e-learning provides the opportunity to create an environment focused on the student (student centered), where students have a more active role in the teaching/learning process. Learning using ICT is characterized by being interactive, easily accessible, distributed and also heavily dependent on the Internet and the World Wide Web.

Technological applications and the alternatives to use them have evolved in such a way that the

Material published as part of this publication, either on-line or in print, is copyrighted by the Informing Science Institute. Permission to make digital or paper copy of part or all of these works for personal or classroom use is granted without fee provided that the copies are not made or distributed for profit or commercial advantage AND that copies 1) bear this notice in full and 2) give the full citation on the first page. It is permissible to abstract these works so long as credit is given. To copy in all other cases or to republish or to post on a server or to redistribute to lists requires specific permission and payment of a fee. Contact HPublisher@InformingScience.orgH to request redistribution permission. use of e-learning systems, tools and learning objects are no longer limited to a desktop, but extended to the use of mobile devices (as the case of PDAs, mobile phones, Smartphones, Tablet PCs and laptops) to get a wider scope of the applications and obtain the benefits that mobile computing offers to the educational sector. 
Due to the increased use of information and communication in the context of higher education, we can see a growing use of online discussion forums by those involved in education (Meyer, 2004). Also, more recently, a number of Web 2.0 tools are in place. However, the use of online discussion forums can provide a number of advantages from the teacher and institution perspective - as it provides a joint memory and record of the interaction effort that takes place in a given context.

Also, online discussion forums have the advantage of leaving all that was discussed recorded to then be analyzed and discussed later (Meyer, 2004) - allowing the realization of studies like the one presented here.

The problem of evaluation, associated with the use of online discussion forums, has been a relevant aspect when instilled in the process of evaluating a particular course. Evaluation may be considered a very complex process leading to several questions and uncertainties for the evaluators.

The evaluation of online discussion forums has aroused the interest of several researchers (Drops, 2003; Maor, 1998; Mesquita, 2007; Meyer, 2004). The simple counting of participations of the actors is not an effective way to measure the quality of interactions. We need a much more complete method, so that the use of discussion forums, in an education context, can be considered in a normal process of evaluation.

It is necessary to perform another type of evaluation by all the participants involved in the use of online discussion forums, in order to verify if these are just one more tool for the teaching/learning process, or if these are really a good tool that enables teachers to promote learning for the students.

This type of evaluation is the flow experience introduced by Mihaly Csikszentmihalyi. The flow experience means the sensation that people feel when they are fully involved in what they do, i.e. if they like the experience and want to repeat it. For students to be involved in what they do, it is necessary to be in the presence of this flow.

The paper is organized in eight sections. A number of concepts concerning the use of ICT in learning are presented in the first section. The following section introduces collaborative environments, explaining the benefits and concerns of these types of environments in the learning process. In the next section are presented online discussion forums and why these changed the processes of teaching and learning and, additionally are briefly presented two examples of these types of forums. Sections four and five provide an overview about how we can evaluate an online discussion forum and how we can measure if a student is in fact learning when using these tools. The following two sections present the used scenario, the gathered data and the discussion of results. Finally a number of conclusions are presented where mainly differences between the use of desktop and laptops are stressed.

\section{The Use of ICT in Learning}

\section{E-Learning}

E-learning comes from the application of the information and communication technologies to the educational area, leading to the creation of a new type of learning, fostering a revolution in the human capital development. This process of teaching and learning allows the learner to have time to learn at their own pace, with the assistance of a tutor, without losing the ability to interact with other participants of their course (Machado, 2001).

E-learning has many advantages because it allows students to: learn at their own pace, deepen their contents, reduce costs and inconveniences associated with traveling to the training center, 
enable training to those who have no possibility to leave their workplace and simplify training access for people with special needs.

However, such teaching does not fit all people: they must be more motivated and more autonomous than in a traditional classroom, some experience in using computers and the Internet and some basic competences for the use of technology (Lima \& Capitão, 2003).

Gambin, cited by Torstein (2007) states that distance education can follow two different directions: one called "The individual and flexible model", which gives the student the freedom to start when they want and at their own pace; the other, called "The extensible teaching model", assumes that students are organized into groups and requires that they meet regularly in an area of study and use new technologies such as video conferencing, radio and television (Torstein \& Aleksander, 2007).

According to the type of model that we can use in teaching, we can consider two high level types of models: the student-centered and the teacher-centered models (Bermejo, 2005).

In the student-centered model, teaching focuses on improving techniques for students to learn better. In this type of model the student is responsible for his or her own learning process. In the teacher-centered model, students are passive elements, teachers shape their students, leading often to a individualistic behavior by the students (Bermejo, 2005).

The following tables summarize the learner-centered and teacher-centered models (Bermejo, 2005) by showing its greatest distinctions.

Table 1 - Teacher-centered and student-centered models (Bermejo, 2005)

\begin{tabular}{|c|c|c|c|}
\hline \multicolumn{2}{|c|}{ Teacher-centered model } & \multicolumn{2}{c|}{ Student-centered model } \\
\hline Teacher & Student & Teacher & Student \\
\hline Actors & Spectators & Coach & Active players \\
\hline $\begin{array}{c}\text { Knowledge } \\
\text { transfers }\end{array}$ & $\begin{array}{c}\text { Repeat this knowl- } \\
\text { edge at exams }\end{array}$ & $\begin{array}{c}\text { Both belong to a society of knowl- } \\
\text { edge creation and exploitation }\end{array}$ \\
\hline Active & Liabilities & \multicolumn{2}{|c|}{ Active } \\
\hline Concentrated on the final grade & Focused on understanding \\
\hline
\end{tabular}

Considering our context, the use of new technologies in the student-centered model enforces (Bricall, 2004):

- Group work: Computer networks facilitate group work. Students in groups try to improve their own learning process and also the learning of the other group members. All members of a group work in the same direction in order to all reach the same goal, searching each one, beneficial results for the group;

- Articulated Communication: Students may send emails with questions to their teachers and to their own colleagues. Another way for students to make questions or discuss anything about a particular subject is through the use of forums. Forums, as opposed to a classroom discussion, has the advantage of all that is discussed is written and recorded, so that other students can later review what was already discussed.

Companies that are aware of the importance of training for greater competitiveness will take full advantage of the e-learning solutions. Its use to optimize the performance of its employees is, for 
businesses, a key component for the optimization of their business (Machado, 2001), and part of any successful knowledge management strategy in an modern organization.

Also, in recent years, there has been a huge investment in changing the paradigm of education, which led to great efforts of change in the educational technologies. As the economy requires that people acquire new knowledge and new practices in periods of time increasingly short and in effective ways, the advancement of technologies provides a set of tools that enables us to support teaching in a more customized, flexible, portable and always available way. Thus let the way for government organizations and educational institutions to adopt these techniques of e-learning. However, it is necessary to understand the phenomenon, take the correct strategic decisions and adapt these techniques to their environment (Zhang, Zhao, Zhou, \& Nunamaker, 2004).

\section{M-Learning}

Quin cited by (Corbeil \& Valdes-Corbeil, 2007) states that m-learning is the interaction of mobile computing (small applications, portable, and wireless communication devices) with e-learning (learning facilitated and supported through information and communication technologies).

We can see a widespread use of mobile devices in our modern world: mobile phones, PDA's, MP3 players, portable gaming devices, Tablet PCs and laptops, which predominate in our everyday lives. More recently, devices as the Apple iPad and Amazon Kindle are being selling in millions, making mobiles devices the greater group of appliances for dealing with digital information.

From children to older people, they are increasingly linked with each other, communicating through communication technologies, something that didn't happen a few years ago and which provides new opportunities and challenges.

There are a number of mobile devices that can be considered for an m-learning environment (Corbeil \& Valdes-Corbeil, 2007): iPod, MP3 Players, PDA, USB drive, E-Book Readers, Smart Phone, Ultra-Mobile PC (UMPC) and Tablet PC and Laptop. These mobile devices have some advantages and disadvantages (Corbeil \& Valdes-Corbeil, 2007). One of the biggest advantages of mobile devices, when compared with desktops, is its ubiquity. Using mobile devices, people can exchange any kind of information, any time, anywhere

\section{Collaborative Environments}

Collaborative learning is an act that results in a coordinated process of building and solving a particular problem (Roschelle \& Teasley, 1995). It is a learning approach that fits better with nowadays modern information society requirements.

Collaborative learning provides an environment that can animate and enrich the learning process. The participation of various people in a collaborative environment permits the creation of a more realistic educational system in a particular social context, thereby increasing the effectiveness of the system. This type of environment helps to sustain the interest of the student, providing a more natural habitat (Kumar, 1996).

To learn in a collaborative environment, we need to follow these characteristics (Landsberger, 2008; Salomon, 1992):

- Develop and share a common goal;

- Contribute to the understanding of the problem;

- Work, respond and understand the issues of other members;

- Assign responsibilities for all elements of the group; 
- Dependency between group members so that everyone understands that the group's success depends from everyone.

Collaborative environments contain behaviors that improve learning. These environments contribute in a positive way for both situations where the participants are physically or through technology, communicating with each others (Curtis \& Lawson, 2001).

Garrison, Anderson, \& Archer (2001) report that through collaborative environments, participants gain a deeper learning, a shared understanding, a critical thinking and a retention of long-term learning, being these the main benefits when engaged in this type of learning activities.

Dillenbourg (1999) defines collaborative learning as a situation where two or more people try to learn something in common and together. Each element of this definition can be interpreted in several ways:

- "Two or more persons" may be interpreted as a pair of people, a small group (3 to 5 persons), one class (20 to 30 people), community (a hundred or a thousand people) or a company (one hundred thousand people), etc.;

- "Learn something" can be interpreted as an accompaniment to a course, a given lecture of a discipline, solving a problem, etc.;

- "Together" can be interpreted as different forms of interaction: face to face or through the new technologies of information and communication.

- A group of people can never reach a perfect consensus of all of life, they need only to reach a reasonable consensus in order to continue the job they are doing (Clark \& Brennan, 1991).

The use of information activities has been considered crucial to the success of collaborative activities (Liu, Tao, \& Nee, 2008).

Nowadays, we see daily information activities, since we go to the Internet and we see appealing symbols about something new, the publicity that we receive in our mailboxes at home, the SMS that we receive to inform us of new promotions. Due to a competitive society that we live in, it is crucial that such information activities occur smoothly. We need to react and deal with them, so that we and our society can survive.

The same is true in education, that is, if there is a greater volume of information activities the greater is the students' attention. If students have information about what is happening in a particular subject, the greater is the interest of students, as demonstrated by (Liu, et al., 2008).

It is necessary that the group members are aware what each is doing, so that the collaboration between them can succeed (Gutwin, Greenberg, \& Roseman, 1996).

In a collaborative environment, it is necessary to have social awareness of other members, this is, if they are reachable or not, if they are well prepared or not and if they can be disturbed. This social knowledge is essential because we can act according to their situation, for example, if one if the group elements is sick maybe we should save the discussion for another day (Tollmar, Sandor, \& Schmer, 1996) - this can be an disadvantage regarding this strategy.

Information services have been developed in collaborative environments, in order to monitor and notify members of the group if any work has been done during the group activity (Jang, Steinfield, \& Pfaff, 2000; Prinz \& Gross, 2001).

Since the notion of cooperation is inherent in collaborative learning, research can also be applied to collaborative learning environments. Both the cooperative and collaborative learning are built around the idea of socially constructed knowledge where interaction between participants play an important role (Gouveia, 2001). 
The two terms (cooperative learning and collaborative) are therefore often used synonymously, and there is a considerable ambiguity among them (Johnson \& Johnson, 1996).

Sometimes the collaborative and cooperative environments can be interpreted in the same way, but these two types of environments have different aspects.

Dillenbourg and Schneider (1995) make a distinction between cooperative and collaborative learning. They indicate that cooperative learning is a protocol, which at the beginning the initial task is subdivided into subtasks, so that the various participants are able to develop them independently. Collaborative learning describes situations where two or more subjects are built synchronously and interactively in order to reach a common solution to a problem (Dillenbourg \& Schneider, 1995).

Cooperative learning generally leaves the authority structures unchanged. The end is defined in the beginning by an instructor, who also describes the means by which the objective will be achieved and evaluate the whole process (Gouveia, 2001). Johnson \& Johnson (1996) reports that cooperative learning is based on the use of small groups, so that students can work together to maximize the learning of them self's and to others.

Collaborative learning can be also cooperative, but it takes all participants a step forward: involving participants in a self-reflective process that often generates a series of questions, "meaning" and "power" and that forces them to confront issues that are implicit in any process of learning in the classroom, although they are rarely explicitly defined and treated (Gouveia, 2001).

\section{Online Discussion Forums}

In the growing context of the use of digital media to support the business of teaching and learning in higher education institutions, there has also been an increased use of online discussions. This enhancement was due to the increasing use of the information technologies and communication, in the context of courses in higher education, which are related with their school activities, applications of discussions and interactions with issues associated with objects of knowledge.

This new reality changes the processes of teaching and learning and allows students to interact with teachers and other colleagues on various issues, more openly, more often and more easily. One of the advantages of online discussions is that it leaves recorded everything that was written to then be analyzed and discussed whenever possible (Meyer, 2004), providing a memory of the work done, giving the opportunity to evaluate the interactions or even to analyze the results of the work done.

These online discussion forums are important factors for the virtual communities and can be considered a well fitted collaborative tool, so that students can make the best environment possible for learning.

The virtual learning communities, where students can interact with the content, with technology, and more importantly, with each others, provides a powerful approach in distance learning environment (McLellan, 1998).

For a collaborative learning to be successful, it is crucial that students feel part of a learning community, where their contributions can add knowledge to the community in which he is involved and where the spirit of community is promoted through social interactions (Benford, Bowers, Fahlén, Greenhalgh, \& Snowdon, 1995).

The virtual learning communities have the potential to solve problems in a distance learning environment (Augar, Raitman, \& Zhou, 2004) and provide a workable context to leverage the learning potential of each of the group participants. 
There are many online discussion forums, available on the Internet. Many of them are free and easily used in a higher education context. That allows students to work collaboratively, to discuss various topics with each other and produce a collective memory of its activity. Google Groups (Figure 1) and Yahoo Groups (Figure 2) are just two examples of the many online discussion forums that can be found.

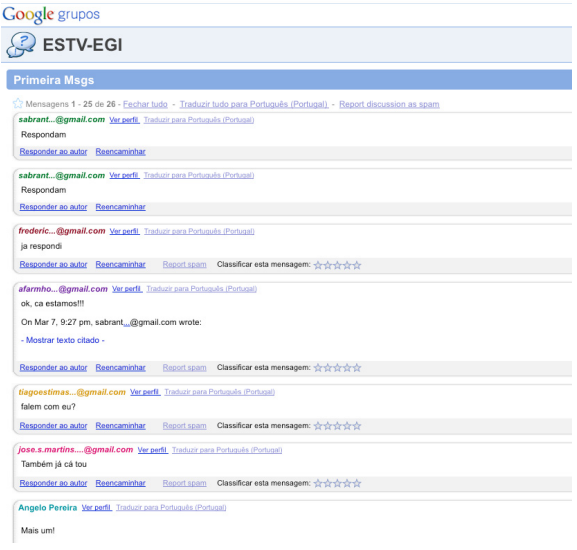

Figure 1 - Google Groups

Google Groups (http://groups.google.pt) is a service created by Google, which allows participants to discuss about a particular subject of interest among the participants of this group. Participants can either discuss using the electronic mail (e-mail) or by using a Web page provided by Google, requiring, for this last option, an e-mail account at gmail (the email service from Google). Google Groups besides allowing discussions of various users online, this service also allows the creation of Web pages for the group, where the users can adjust the visual aspect of each page, or even insert images and change the background colors. It also allows file sharing among group members and access to personal information of each group member.

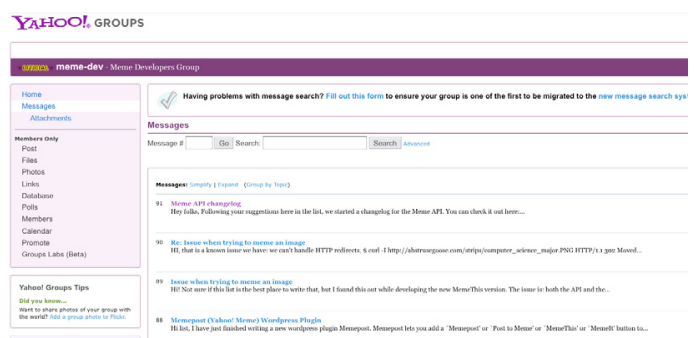

Figure 2 - Yahoo Groups

Yahoo Groups (http://groups.yahoo.com) is a service similar to Google Groups. It is a discussion group developed by the company Yahoo. Yahoo groups as like Google groups offers a set of groups of interest, in which users can register themselves in. The Yahoo Groups allows participants to share photos with each other and share a calendar of events. 


\section{Evaluating Online Discussion Forums}

Although the use of forums in the context of higher education is already widely used, some issues associated with its utilization arise, such as, what is its potential and how can we make its own evaluation.

The potential of these online discussion forums has been widely discussed in the literature (Roberts \& McInnerney, 2007; Roschelle, Rosas, \& Nussbaum, 2005) and can be summarized as being a collaborative learning environment supported by computers, that if implemented properly, can become an ideal environment where interaction between students predominates and also where members participating in a collaborative environment, aim to learn what was proposed and can maintain a relationship between the group members.

The evaluation issue is quite complex and raises many questions and uncertainties to the evaluator. According to Santos (2003), this fact “... certainly has to do with the meanings and concepts of assessment practices that each teacher has, as well as their own evaluative experience".

So what does the term "evaluate" mean? In the dictionary (PRIBERAM, 2009) the term "evaluate" means "to determine the value of", "understand", "judge", "appreciate". Thus we can say, evaluating student's results is an understanding, appreciation and judgment of their work, by the teacher, using different set of instruments in order to determine a qualitative or quantitative value.

As Santos (2006) refers, there is on teachers, unequal conceptions of the term evaluate and its functions of assessment, as well as different forms of action (Pinto \& Santos, 2006). Another important issue, for this research, will be the evaluation of students participating in online discussion forums. There are a number of studies using various forms of assessment to get in use in online discussion forums (Drops, 2003; Maor, 1998; Mesquita, 2007; Meyer, 2004).

With the simple counting of posts of each participant in an online discussion forum, you cannot measure the quality of interactions. Moreover, we can state that quality is not synonymous with quantity (Drops, 2003).

In turn, Maor enabled students to use discussion forums to discuss about the issue of computers in education, with a different leader every week for the online discussion (Maor, 1998). Based on the activities of the students, the author has created a database with the following fields: subject, the leader of the discussion, the topic of the discussion and the involvement of the student in the discussion. As he reads the messages, he classifies each of the posts, having in consideration the following terms: the student initialized a redundant conversation, presented an issue or address of a page, is leading the discussion or is just to answer a question.

Meyer used four different kinds of methods to analyze seventeen online forums of a doctoral program in order to validate its efficiency (Meyer, 2004). In particular, for the present study, we considered the approach proposed by (Mesquita, 2007), who follows a model that basically follows three steps:

- Classify each message of each student as being significant or not significant. This is, messages like "Thank you", "until tomorrow", "Hello", are classified as non-significant and other messages that are related to the content of the topic in question are classified as significant;

- Once each message has been classified, we should classify each one according to a scale of 1 to 3 (1 - Positive, 2 - Good, 3 - Very Good);

- Finally, calculate the number of meaningful messages through their multiplication factor, this is, multiply the number of messages with a classification of very good by three, multiply the messages with a classification of good by two and finally multiply the messages 
with a classification of positive by 1 , adding in the end, all these components. After this operation is performed, it is necessary to convert these values to a qualitative classification. As for the conversion of these values we can use as basis, the student who has more meaningful messages, this will be awarded with 20 points and the others will use the direct proportionality. In this model, the student who has written more posts does not necessarily have better ratings than the student who has participated less. For example, one student could have written 20 posts with only 3 messages classified as good and 2 as positive, another student could have written only 10 posts, all of which are classified as very good, having this student a better classification than the first. For example, student 1 has one very good message, two good messages and both and one positive message, student 2 has zero very good messages, one good message and one positive message, the student $\mathrm{n}$ has one message very good, and has one good and positive message.

Table 2 - Evaluation of online discussion forums (Mesquita, 2007)

\begin{tabular}{|c|c|c|c|c|c|}
\hline \multirow[b]{3}{*}{ Student } & \multicolumn{5}{|c|}{ Number of messages } \\
\hline & \multicolumn{3}{|c|}{ Significant } & \multirow[t]{2}{*}{ Not significant } & \multirow[t]{2}{*}{ Total } \\
\hline & 3 & 2 & 1 & & \\
\hline Student 1 & 1 & 2 & 1 & 3 & 7 \\
\hline Student 2 & 0 & 1 & 1 & 4 & 6 \\
\hline \multicolumn{6}{|l|}{$\cdots$} \\
\hline Student $\mathrm{n}$ & 1 & 1 & 1 & 1 & 4 \\
\hline
\end{tabular}

It is the algorithm described by Mesquita (2007) that serves as the base for the current evaluation of the quality and the participation of the students in an online discussion forum. This approach assumes that we are in a collaborative learning environment and that the teacher has with him an evaluation grid in order to grade each of the messages of the various participants.

In conclusion, the formula follows:

Partial classification of the student $=$ nrespx $*$ ntipo $1+$ nrespx $*$ ntipo $2+$ nrespx $*$ ntipo3.

Where nrespx represents the number of significant responses and ntipo refers to a scale of 1 to 3 (1 - Positive, 2 - Good, 3 - Very Good)

The student's final grade is calculated on the basis of the student who has more meaningful messages (partial classification of the student) who will be awarded with 20 points and the other using the proportionality rule.

\section{The Flow Experience}

An aspect related with the interaction of the users with collaborative environments has to see with the flow experience introduced by Csikszentmihalyi (1975). The experience of the flow means the sensation that people feel when they are completely involved in what they are doing, that is, people like the experience and want to repeat it (Csikszentmihalyi, 1982). This means that for students to be involved with collaborative environments, it is necessary that they presence the flow state. 
The theory of the flow allows us to measure the interaction of users with the computer systems, verifying if these are more or less playfulness (Trevino \& Webster, 1992). The flow experience is used in this research to characterize the interaction between the human and the new technologies (Trevino \& Webster, 1992).

When one is in the presence of the flow state, this will bring to the users, a sense of pleasure of what he is doing. This satisfaction will encourage the user to repeat the task again (Webster, Trevino, \& Ryan, 1993).

Csikszentmihalyi says that a person who is in the presence of the flow state has the following characteristics (Csikszentmihalyi, 1975, 1990):

- Clear goals and immediate feedback;

- Equilibrium between the level of challenge and personal skill;

- Merging of action and awareness;

- Focused concentration;

- Sense of potential control;

- Loss of self-consciousness;

- Time distortion;

- Autotelic or self-rewarding experience.

For a person to be in the presence of the flow experience it is necessary a balance between the level of challenge and personal skill (Csikszentmihalyi, 1982) as illustrated in Figure 3.

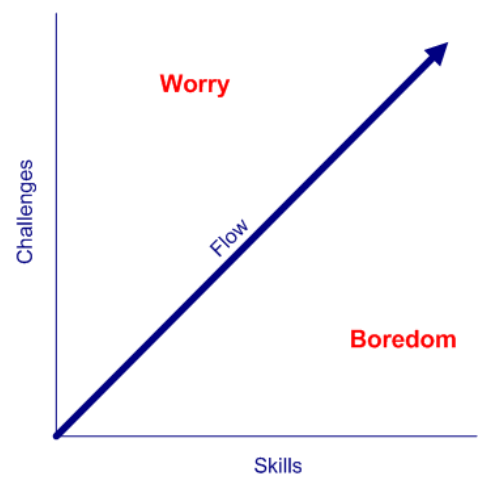

Figure 3 - Flow Experience (Csikszentmihalyi, 1982).

The sensation of an excellent experience in the accomplishment of any day by day task is our reason of living. If we do not feel this excellent experience with our everyday tasks, we will question our self, if it is worth living (Csikszentmihalyi, 1982) - so the concept of flow experience is also related to more high level concept of the individual self.

Previous researches have used the flow experience to measure playfulness, involvement, satisfaction and other states with the involvement in computational environments (Chen, Wigand, \& Nilan, 2000; Ghani \& Deshpande, 1994; Novak \& Hoffman, 1997; Novak, Hoffman, \& Yung, 2000; Trevino \& Webster, 1992) 
Trevino and Webster (1992) define four dimensions for the flow experience:

- Control;

- Attention Focus;

- Curiosity;

- Intrinsic Interest.

There is one more dimension - sense of time -, that is also important to measure the flow state (McKenna \& Lee, 2005). All the five described dimensions can be stated as follows:

- Control: Individuals should experience, feelings in control, within computer interactions (Csikszentmihalyi, 1975).

- Attention Focus: Attention focus is another important element of flow. When individuals are in the flow state, their minds are narrowed to what they are doing, filtering out irrelevant thoughts and perceptions (Webster, et al., 1993).

- Curiosity: Curiosity is aroused when in the flow state. The curiosity sensation can be aroused through varied, new and admirable stimulations. For example, the new technologies will be able to cause this sensation of curiosity through colours and sounds (Webster, et al., 1993).

- Intrinsic Interest: When people feel they are in the flow state, these are involved for the amusement and pleasure (Webster, et al., 1993).

- Sense of time: When people feel they are in the flow state, there is a perceptual transformation of time, characterized by the sensation of time slowing down or speeding up (McKenna \& Lee, 2005).

People who interact with computers, with an entertainment spirit, transmit a much more positive experience, of those, who use computers for obligation (Webster, et al., 1993).

\section{The Scenario}

Nowadays, most people all around the world use mobile devices. Due to the advance and size of these new technologies, users can carry them anywhere; can connect with a wide range of information anywhere they go.

Despite the widespread of use of mobile devices today, there is a lack of reference to identify the advantages and disadvantages of the m-learning as a collaborative environment, this is, we can not see the m-learning as an extension of e-learning but a rupture in the process of teaching and learning.

The course used for our experiment was Introduction to Computer Science; this course was used by the students in order to conduct an experiment based on collaborative environments, using information and communication technologies.

Based on what was explained earlier, and in accordance with the objective of the course, students will have several classes to cover the various objectives of the course, being one of these classes, dedicated to collaborative environments. After this, students will be required to perform a task group using a collaborative platform.

Detailed description of the scenario:

1. The teacher divides the students into 5 groups, each group with 5 to 6 individuals; 
2. The elements of the groups will select one of the topics proposed by the teacher, these themes are related with Facebook, such as:

- Find friends and cultivate friendships;

- Create an group of interest;

- Defend a cause;

- Advertise an event;

- Present an event.

3. After selecting the theme, the groups will begin to conduct their work using only Google Groups for discussion and Google Docs for the report and the final presentation;

4. Students will have 4 weeks to accomplish their work;

5. After these four weeks, students will submit a written report and a presentation of their work.

Application of the scenario:

1. First, before beginning the collaborative work, students will have to complete an initial investigation, throughout a survey, in order to validate a number of aspects related to the use of tools and other issues related to collaborative environments;

2. After completing this investigation, students will depart for the development of the final work in which they responsible to do, using the tools suggested by the teacher.

3. After 4 weeks from the beginning of the work, students will deliver the final report to the teacher and make a presentation to their classmates about their work.

4. At the day of the submission of the final work, all elements of the groups will complete a final survey in order to validate aspects related with the collaborative tools used.

\section{The Study}

To evaluate the flow experience and to verify its occurrence in collaborative tools, an experiment was carried through, involving students from a university school. The main tool used was Google Groups, for this experiment. This chapter presents the carried through experiment, the data obtained, as well as the statistical procedures applied.

Previously to this study, a test with five students was done, to analyze the effectiveness of the survey. From this previous study, we concluded that some questions were ambiguous for the population studied.

The survey was passed through the Internet with the help of "LimeSurvey". The data collection was performed in the first week of November of 2009.

The Instruments used were Google Groups, Google Docs and Facebook and a survey consisting on some questions, in order to verify, in the end of the study, if the students were in the presence of the flow state. This survey will use the four dimensions: control, attention focus, curiosity and intrinsic interest (Webster, et al., 1993), as well as the dimension sense of time (McKenna \& Lee, 2005). Beside these questions, this survey also contains other generic questions. All the related questions from this survey were built on a Likert scale of five points, since one (I totally disagree) up to five (I totally agree). Two questions for each dimension were elaborated.

\section{Sample}

This study intends to determine if the students inquired are in the flow state and what is the quality of the responses given by the students. The data has been collected through one hundred and twelve surveys of students. The surveys have been submitted to a rigorous test, having not excluded any individual; therefore, the sample consisted on one hundred and twelve valid surveys. The criteria of exclusion of inquiries were: students who had not discriminated their sex or age in 
the survey; students with incoherent answers throughout the survey (e.g., answers that always presented values in the extremities of the scales, or incompatible); students who left $80 \%$ of the survey in blank. Once, one hundred and twelve valid inquiries were obtained, the sample is considered sufficiently satisfactory.

The statistical treatment of the data and the respective procedure (Pereira, 2002; Pestana \& Gagueiro, 2005), that will be presented, was carried through the software "S.P.S.S. - Statistical Package for the Social Sciences" (version 17.0 for Windows, http://www.spss.com/):

- Descriptive Statistics of the variables in the study;

- Evaluation of the index of internal consistency (Cronbach's alpha) for the dimensions of the flow experience;

- Correlation between the variables of the flow;

- Factor analysis in order to reduce the number of variables.

\section{Analysis}

This study was composed of $78.57 \%$ males and $84.82 \%$ had ages between sixteen and twenty four years.

The majority of the respondents used the laptop (72.32\%) to access the tools for the project development, followed by the Desktop (27.68\%).

We verified that Cronbach's alpha is always superior to 0.7 , being able to conclude that the data is related to one same dimension, that is, the questions of the survey for the use of Google Groups, allowed us to determine if the individual finds himself in the presence of the flow experience, for students using a laptop or a Desktop.

To determine how the variables are correlated with each of the different devices used (laptop and Desktop), a correlation matrix was created for both types of the devices, where the correlation coefficient, $\mathrm{R}$, is presented, that is a measure of the linear association between two variables. We can conclude from the correlation analysis that the correlation between the variables, for laptops, has a greater number of variables positively correlated than the desktop.

After the studies mentioned previously, we used the factor analysis in order to reduce the number of variables, both for laptops and desktops.

The extraction of the factors is given by considering the percentage of variance explained by the factors for Mobile Devices in Table 2.

Table 3 - Number of factors to be retained (Mobile Devices)

\begin{tabular}{|c|c|c|c|}
\hline \multirow[b]{2}{*}{ Component } & \multicolumn{3}{|c|}{$\begin{array}{c}\text { Mobile Devices } \\
\text { Initial Eigenvalues }\end{array}$} \\
\hline & Total & $\begin{array}{l}\% \text { of } \mathrm{Va}- \\
\text { riance }\end{array}$ & $\begin{array}{c}\text { Cumulative } \\
\%\end{array}$ \\
\hline 1 & 2.371 & 47.422 & 47.422 \\
\hline 2 & .881 & 17.625 & 65.047 \\
\hline 3 & .707 & 14.136 & 79.184 \\
\hline 4 & .631 & 12.613 & 91.797 \\
\hline 5 & .410 & 8.203 & 100.000 \\
\hline
\end{tabular}


Also the same process of the extraction of the factors is given by considering the percentage of variance explained by the factors for Desktop devices in Table 3.

Table 4 - Number of factors to be retained (Desktop)

\begin{tabular}{l|ccc}
\hline \hline & \multicolumn{3}{c}{ Desktop } \\
Initial Eigenvalues \\
Component & Total & $\begin{array}{c}\text { \% of- } \\
\text { riance }\end{array}$ & $\begin{array}{c}\text { Cumulative } \\
\%\end{array}$ \\
\hline 1 & 2.374 & 47.475 & 47.475 \\
2 & 1.053 & 21.053 & 68.528 \\
3 & .704 & 14.077 & 82.604 \\
4 & .565 & 11.301 & 93.905 \\
5 & .305 & 6.095 & 100.000 \\
\hline \hline
\end{tabular}

From the previous table, we can observe, for each of the factors (or components), which is its own value (eigenvalue) and the percentage of the total variation occurring in the five variables.

To set the number of components to be retained, we choose, by default, those that have eigenvalues greater than one. If the total variance explained by the factors retained is less than $60 \%$, then, at least, one more factor should always be selected. Thus, for this case study, two factors were retained in each type of device. For the mobile device, it appears that the first factor explains $47.422 \%$ of the total variation and the second $17.625 \%$, both explaining $65.047 \%$ of the total variation that exists in the five original variables. For the Desktop, the first factor explains $47.475 \%$ and the second $21.053 \%$, explaining both, $68.528 \%$ of the total variation.

The matrix of components after rotation (Varimax method) aims to exaggerate the value of the coefficients that relates each variable to the factors retained, so that each variable can be associated with only one factor. The higher the value of the coefficient that relates one variable to a component, the greater is the relationship between them. We present below the matrix of components after rotation (Table 5) and the bold factor associated with each variable.

Table 5 - The matrix of components after rotation

\begin{tabular}{lcccc}
\hline \hline & \multicolumn{2}{c}{ Mobile Device } & \multicolumn{2}{c}{ Desktop } \\
& 1 & 2 & 1 & 2 \\
\hline Component &. $\mathbf{6 1 4}$ & $\mathbf{. 7 5 1}$ & .001 \\
Control & .411 & .317 & .011 & $\mathbf{. 9 5 5}$ \\
Curiosity & $\mathbf{. 6 5 3}$ & .057 & $\mathbf{. 7 1 4}$ & .461 \\
Intrinsic Interest & $\mathbf{. 8 7 4}$ & .383 & $\mathbf{. 8 4 1}$ & .155 \\
Sense of time & $\mathbf{. 7 0 5}$ &. $\mathbf{8 7 7}$ & $\mathbf{. 6 9 4}$ & .121 \\
\hline \hline
\end{tabular}


Having concluded the following for the case of the laptops:

Factor group 1: (Intrinsic Interest, Control and Curiosity)

Factor group 2: (Attention Focus and Sense of time)

And for the case of the desktops:

Factor group 1: (Attention Focus, Sense of time, Intrinsic Interest and Curiosity)

Factor group 2: (Control)

Relatively to the evaluation of the students for online discussion forums (Table 6), we can conclude that there has been a total of 661 messages, where 238 where messages that has been classified as Very Good, 150 as Good, 203 as Positive and 70 of the messages has been classified as not significant, this is, these messages were considered not being valid for the discussion between the participants. Separating these messages for the students who have used do laptop and the desktop, we can reach to the conclusion that the students who have used the laptop have sent more messages (455) then the students who have used the desktop (136). For the users who used the laptop, 185 were considered Very Good, 113 were Good, 157 classified as Positive and 45 classified as not significant. As for the users of the desktop, 53 were messages classified as Very Good, 37 classified as Good, 46 as Positive and 25 as not significant.

Table 6 - number of messages (without multiplication factor)

\begin{tabular}{|c|c|c|c|c|c|}
\hline \multicolumn{9}{c}{ Significant } & $\begin{array}{c}\text { Number of messages } \\
\text { Not Significant }\end{array}$ & Total (Significant) \\
\hline & $\mathbf{3}$ & $\mathbf{2}$ & $\mathbf{1}$ & & 455 \\
\hline Laptop & 185 & 113 & 157 & 45 & 136 \\
\hline Desktop & 53 & 37 & 46 & 25 & \\
\hline \hline
\end{tabular}

In table 7 we can see the number of meaningful messages through their multiplication factor, having the laptop users a meaningful value greater than the desktop users.

Table 7 - number of messages (with multiplication factor)

\begin{tabular}{|c|c|c|c|c|c|}
\hline \multicolumn{9}{c}{ Number of messages } \\
\hline \hline & $\mathbf{3}$ & $\mathbf{2}$ & $\mathbf{1}$ & & Total (Significant) \\
\hline Laptop & 185 & 113 & 157 & 45 & 938 \\
\hline Desktop & 53 & 37 & 46 & 25 & 279 \\
\hline \hline
\end{tabular}

However, we need to consider the fact that the number of users using the laptop is greater than the number of the desktop users. The tables shown previously are not obvious about the medium number of messages sent by each kind of user for the two different types of devices. As result, we provide in table 8 the medium number of messages sent by each student for the laptop and desktop in order to allow a comparison based on relative numbers and taking into account the different dimension of the two groups. 
Table 8 - Medium number of messages

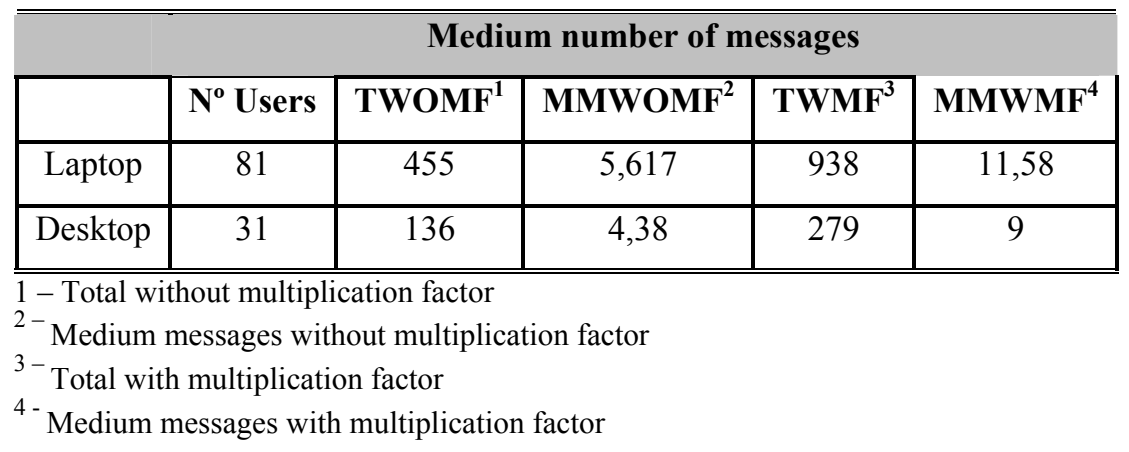

As we can conclude from table 8 , the medium number of messages sent by each student for that laptop is greater as also their multiplication factor (message importance) than for the desktop users. These results enforce the ones provided for the flow experience and show a better performance for the laptop users both in the number of the message produced (more 1,237 messages by user) as, in a more significant way, in its importance (value, considered the multiplication factor is 2,58 higher).

\section{Conclusions}

In order to evaluate the use of mobile devices and desktops and the potential of mobile devices in collaborative environments versus desktops, it was performed an experiment involving students of higher education. This study has the main objective to evaluate if the students that use laptops or desktops are in the flow experience, which of them are more in the flow experience and what were the type of messages sent by each of these different kind of users (Very Good, Good, Positive and not significant).

Most people all around the world use mobile devices. Due to the advance of the new technologies, and its size, users can carry them anywhere; can connect with a wide range of information to anywhere whenever they go.

Despite the widespread use of mobile devices today, there is a lack of reference to identify the advantages and disadvantages of the m-learning in collaborative environments, this is, we can not see the m-learning as an extension of e-learning but a rupture in the process of teaching and learning.

The analysis of data allows us to conclude that the majority of the students were males, had ages between sixteen and twenty four years and that most of the students have already used discussion forums.

When going further to the analysis of the data, we verified that the variables described all the same characteristic (threw the determination of the Cronbach's alpha), that is, the variables describe the flow experience.

We can conclude from the correlation analysis that the correlation between the variables, for laptops, has a greater number of variables positively correlated than the desktop.

From the factor analysis it was possible to isolate two factors that explain the majority of the total variation. Such factors had been Factor group 1: (Intrinsic Interest, Control and Curiosity), Factor group 2: (Attention Focus and Sense of time) for the laptops and Factor group 1: (Attention Focus, Sense of time, Intrinsic Interest and Curiosity) Factor group 2: (Control) for the desktops. 
In order to determine the presence of the flow experience for each type of device, it was verified that, on average, the students were above value three (Likert scale of five points), that is, the majority of the students, in each of the different devices used (laptop and desktop), are in the presence of the flow experience, for the five variables mentioned for this study (attention focus, curiosity, control, intrinsic interest and sense of time). We can also see, that the average of the five variables associated with the flow experience, for students who used the laptops, were greater than those using the desktop to access the tools of the project development.

From this study we can conclude that the flow experience exists for people that use Google Groups, both for people that used the laptop or even the desktop, but having a more positively effect for users of the laptop.

This report also proposed an algorithm that allows us to measure the quality of the interventions by the various participants in an online discussion forum. It can be considered, that this algorithm is one of the possible way, among others, to assess the participation of online discussion forums.

To use this algorithm to evaluate a online discussion forum it is necessary that the evaluator has the following basic elements: a online discussion forum, a group of students that interact on the forum, a unique identifier for each participant, a set of messages sent by each of the participants and an evaluation grid, as described above, so that the evaluator can mark each intervention for each participant. The analysis of data allows us to conclude that the students who have used the laptop have sent more messages (455) then the students who have used the desktop (136). For the users who used the laptop, 185 were considered Very Good, 113 were Good, 157 classified as Positive and 45 classified as not significant. As for the users of the desktop, 53 were messages classified as Very Good, 37 classified as Good, 46 as Positive and 25 as not significant. Considering the medium number of messages sent by the laptop and desktop users, 5.617 messages were sent by the laptop users and 4.38 by the desktop users, when not considering the multiplication factor. When considering the multiplication factor, 11.58 were sent by the laptop users and 9 by the desktop users.

With these statements we can say that Google Groups is a good way for students to learn when using laptops and desktops. The laptop users have a more positive effect when using Google groups than the desktop users. We also verified that the laptop users participate more on online discussion forums. We can also say that, m-learning when associated with the usage of Google Groups, it is a good tool for students to learn.

These results can be considered good news as the number of mobiles devices are rising over and over and the potential for m-learning will follow to eventually increase the quality of interaction among students and their flow of experience and engaging with e-learning activities, in particular, the ones oriented to collaborative learning.

\section{References}

Andreas, H., Alexander, N., \& Matthias, M. (2005). Lifelong-learning support by m-learning: example scenarios. Association of Computing Machinery ACM eLearn Magazine, 5.

Augar, N., Raitman, R., \& Zhou, W. (2004). From e-learning to virtual learning community: Bridging the gap. Advances in Web-Based Learning - ICWL 2004 (pp. 301-308).

Benford, S., Bowers, J., Fahlén, L. E., Greenhalgh, C., \& Snowdon, D. (1995). User embodiment in collaborative virtual environments. Paper presented at the the SIGCHI conference on Human Factors in Computing Systems.

Bermejo, S. (2005). Cooperative electronic learning in virtual laboratories through forums Cooperative electronic learning in virtual laboratories through forums. Education, IEEE Transactions on Education, $48(1), 140-149$. 
Bricall, J. M. (2004). University report 2000. Spanish Ministry of Education.

Chen, H., Wigand, R. T., \& Nilan, M. (2000). Exploring Web users' optimal flow experiences. Information Technology \& People, 12(4).

Clark, H. H., \& Brennan, S. (1991). Grounding in communication. Perspectives on Socially Shared Cognition, 127-149.

Corbeil, J. R., \& Valdes-Corbeil, M. E. (2007). Are you ready for mobile learning? EDUCAUSE Quarterly, $30(2), 51-58$.

Csikszentmihalyi, M. (1975). Beyond boredom and anxiety. San Francisco, CA.

Csikszentmihalyi, M. (1982, 1982). Towards a psychology of optimal experience. Paper presented at the Annual Review of Personality and Social Psychology.

Csikszentmihalyi, M. (1990). The psychology of optimal experience. Harper Collins.

Curtis, D. D., \& Lawson, M. J. (2001). Exploring collaborative online learning. Journal for Asynchronous Learning Networks, 5(1), 21-34.

Dillenbourg, P., \& Schneider, D. (1995). Collaborative learning and the internet. Retrieved 1-12-2009, from http://tecfa.unige.ch/tecfa/research/CMC/colla/iccai95 1.html

Drops, G. (2003). Assessing online chat sessions. OnlineCl@ssroom, 1-8.

Garrison, D. R., Anderson, T., \& Archer, W. (2001). Critical thinking and computer conferencing: A model and tool to access cognitive presence. American Journal of Distance Education, 15(1), 7-23.

Ghani, J., \& Deshpande, S. (1994). Task characteristics and the experience of optimal flow in humancomputer interaction. The Journal of Psychology, 128(4), 381-391.

Gouveia, L. M. B. (2001). A visualisation design for sharing knowledge. Lancaster: Lancaster University.

Gutwin, C., Greenberg, S., \& Roseman, M. (1996). Supporting awareness of others in groupware. Paper presented at the Conference companion on Human factors in computing systems: common ground.

Jang, C. Y., Steinfield, C., \& Pfaff, C. (2000). Supporting awareness among virtual teams in a web-based collaborative system: the teamSCOPE system. SIGGROUP Bull., 21(3), 28-34.

Johnson, D. W., \& Johnson, R. T. (1996). Cooperation and the use of technology. In J. M. Spector, M. D., J. van Merrienboer, \& M. P Driscoll (Eds.), Handbook of research for educational communications and technology (pp. 1017-1044). New York: Simon \& Schuster Macmillan.

Kumar, V. S. (1996). Computer-supported collaborative learning: issues for research. Retrieved 1-122009, from http://www.uib.no/People/sinia/CSCL.

Landsberger, J. (2008). Cooperative \& collaborative learning. Retrieved 3-10-2007, from http://www.studygs.net/cooplearn.htm

Lima, J. R., \& Capitão, Z. (2003). e-learning e e-conteudos. Lisboa: Centro Atlântico.

Liu, C. C., Tao, S. Y., \& Nee, J. N. (2008). Bridging the gap between students and computers: Supporting activity awareness for network collaborative learning with GSM network. Behaviour \& Information Technology, 27(2), 127 - 137.

Machado, J. (2001). E-Learning em Portugal. Lisboa: FCA.

Maor, D. (1998). How does one evaluate students' participation and interaction in an Internet-based unit? Paper presented at the 7th Annual Teaching Learning Forum, The University of Western Australia.

McKenna, K., \& Lee, S. (2005). A love affair with MUDs: Flow and social interaction in multi-user dungeons. Retrieved 2007/10/10/ from http://fragment.nl/mirror/various/McKenna et al.nd.A_love affair with muds.html

McLellan, H. (1998). The Internet as a virtual learning community. Journal of Computing in Higher Education, 9(2), 92-112. 
Mesquita, J. S. (2007). b-learning no ensino secundário recorrente - Uma Proposta baseada na construção do conhecimento. Universidade de Aveiro, Aveiro.

Meyer, K. A. (2004). Evaluating online discussions: Four different frames of analysis. Journal of Asynchronous Learning Networks, 8(2), 101-114.

Novak, T. P., \& Hoffman, D. L. (1997). Measuring the flow experience among web users. Vanderbilt University.

Novak, T. P., Hoffman, D. L., \& Yung, Y. (2000). Measuring the customer experience in online environments: A structural modeling approach. Marketing Science, 19(1), 22-42.

Pereira, P. A. (2002). Complementos de Estatística.

Pestana, M., \& Gagueiro, J. (2005). Análise de dados para Ciências Sociais - A complementaridade do SPSS.

Pinto, J., \& Santos, L. (2006). A avaliação numa perspectiva formativa. In U. Aberta (Ed.), Modelos de Avaliação das Aprendizagens (pp. 97-128). Lisboa.

PRIBERAM. (2009). Dicionário Electrónico de Língua Portuguesa.

Prinz, W., \& Gross, T. (2001). Ubiquitous awareness of cooperative activities in a theatre of work. In A. Bode \& W. Karl (Eds.), Fachtagung arbeitsplatzcomputer: Pervasive ubiquitous computing (pp. 135144). APC.

Roberts, T. S., \& McInnerney, J. M. (2007). Seven problems of online group learning (and their solutions). Educational Technology \& Society, 10(4), 257-268.

Roschelle, J., Rosas, R., \& Nussbaum, M. (2005). Towards a design framework for mobile computersupported collaborative learning. CSCL 2005: Computer Supported Collaborative Learning 2005: The Next 10 Years, Proceedings, 520-524.

Roschelle, J., \& Teasley, S. D. (1995). The construction of shared knowledge in collaborative problem solving. Paper presented at the Computer supported collaborative learning.

Salomon, G. (1992). What does the design of effective CSCL require and how do we study its effects? SIGCUE Outlook, 21(3), 62-68.

Tollmar, K., Sandor, O., \& Schmer, A. (1996). Supporting social awareness @ workdesign and experience. Paper presented at the 1996 ACM conference on Computer supported cooperative work.

Torstein, R., \& Aleksander, D. (2007). Mobile distance learning with PDAs: Development and testing of pedagogical and system solutions supporting mobile distance learners. The International Review of Research in Open and Distance Learning, 8(2).

Trevino, L. K., \& Webster, J. (1992). Flow in computer-mediated communication. Communication Research, 19(5), 539-573.

Webster, J., Trevino, L. K., \& Ryan, L. (1993). The dimensionality and correlates of flow in humancomputer interaction. Computer Game Research, 9, 411-426.

Zhang, D., Zhao, J. L., Zhou, L., \& Nunamaker, J. F., Jr. (2004). Can e-learning replace classroom learning? Communications of the ACM, 47(5), 75-79. 


\section{Biographies}

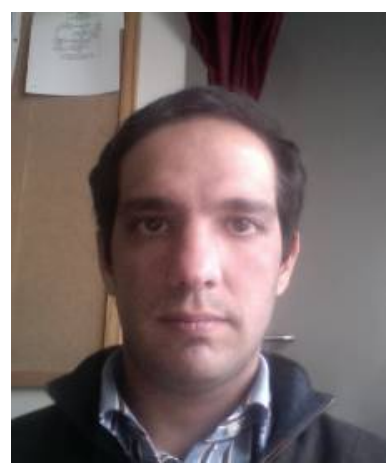

Steven Lopes Abrantes is a teacher at Polytechnic Institute of Viseu. $\mathrm{He}$ is a Phd student at the University of Fernando Pessoa, Porto. He holds a Master degree in Information Management (University of Aveiro, 2007) and a Bachelors degree on Computer Science (University of Coimbra, 2004). His interests are in the application of computer technologies in education, in particular, the use of mobile technologies in distance learning.

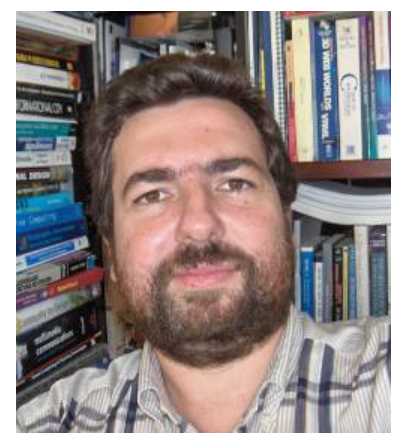

Luis Borges Gouveia is an Associate Professor at University Fernando Pessoa. He holds a PhD in Computer Science (University of Lancaster, 2002) and a Masters degree in Electronic and Computers Engineering (University of Oporto, 1995). His interests are within the impact of information society and digital use both in education and business.

Luis has a Web homepage at http://homepage.ufp.pt/ lmbg 